\title{
Impact of solid fuel particle size upon the propagation of a surface fire through a homogeneous vegetation layer
}

\author{
DOMINIQUE MORVAN, AYMERIC LAMORLETTE \\ Aix-Marseille Université Faculté des Sciences Département de Mécanique \\ Laboratoire M2P2 UMR CNRS 7340 \\ UNIMECA Technopôle de Château Gombert 60 rue Joliot Curie \\ 13453 Marseille cedex 13 FRANCE
}

\begin{abstract}
The aim of this paper is to investigate the role played by the size (thickness) of solid fuel particles upon both the heat transfer and the propagation of a surface fire through a homogeneous vegetation layer. Because all the interactions (mass, momentum, and heat transfer) between the solid fuel layer and the gas phase occur at the interface between these two media, the surface area to volume $(S A / V)$ ratio (inversely proportional to the thickness of the solid fuel particles), which appears in the expression of the specific surface separating these two phases, must affect, more or less significantly, the fire dynamics. This problem has been studied numerically, using a multiphase formulation. Various variables, such as the temperature of the solid fuel, the temperature of the gas, the fire residence time and the heat flux by radiation and convection have been analyzed, in order to understand the role played by the SA/V upon the behaviour of the fire.
\end{abstract}

KEYWORDS: wildfire, modeling, flame spread

\section{NOMENCLATURE LISTING}

\begin{tabular}{|c|c|c|c|}
\hline$a$ & Leaf Area Density (LAD) $\left(\mathrm{m}^{-1}\right)$ & $X$ & Streamwise direction $(\mathrm{m})$ \\
\hline$C_{D}$ & Average drag coefficient & $Y$ & Mass fraction $(\mathrm{kg} / \mathrm{kg})$ \\
\hline$C_{P}$ & Specific heat $\left(\mathrm{J} \mathrm{kg}^{-1} \mathrm{~K}^{-1}\right)$ & $Z$ & Vertical direction (m) \\
\hline$H_{\text {Fuel }}$ & Fuel layer depth & & \\
\hline$g$ & Acceleration of gravitation $\left(\mathrm{m} \mathrm{s}^{-2}\right)$ & & \\
\hline$I$ & Radiation intensity $\left(\mathrm{Wm}^{-2}\right)$ & \multicolumn{2}{|c|}{ Greek } \\
\hline$I_{B}$ & Fire line intensity $\left(\mathrm{W} \mathrm{m}^{-1}\right)$ & $\alpha$ & Volume fraction $\left(\mathrm{m}^{3} / \mathrm{m}^{3}\right)$ \\
\hline$K$ & Turbulence kinetic energy $\left(\mathrm{m}^{2} \mathrm{~s}^{-2}\right)$ & $\varepsilon$ & TKE dissipation rate $\left(\mathrm{m}^{2} \mathrm{~s}^{-3}\right)$ \\
\hline$L A I$ & Leaf Area Index & $\mu$ & Dynamic viscosity $\left(\mathrm{kg} \mathrm{m}^{-1} \mathrm{~s}^{-1}\right)$ \\
\hline & & $\theta$ & Temperature variance $\left(\mathrm{K}^{2}\right)$ \\
\hline$m$ & Mass loss rate $\left(\mathrm{kg} \mathrm{m}^{-1} \mathrm{~s}^{-1}\right)$ & $\rho$ & Density $\left(\mathrm{kg} \mathrm{m}^{-3}\right)$ \\
\hline$P$ & TKE shear production term & $\sigma$ & $\begin{array}{l}\text { Stefan-Boltmann constant } \\
\left(\sim 5.6710^{-8} \mathrm{~W} \mathrm{~m}^{-2} \mathrm{~K}^{-4}\right)\end{array}$ \\
\hline$R O S$ & Fire rate of spread $\left(\mathrm{m} \mathrm{s}^{-1}\right)$ & $\sigma_{a}$ & $\begin{array}{l}\text { coefficient }\left(\mathrm{m}^{-1}\right) \\
\text { Surface area to volume ratio }\end{array}$ \\
\hline$T$ & Temperature $(\mathrm{K})$ & $\sigma_{S}$ & $\mathrm{SA} / \mathrm{V}\left(\mathrm{m}^{-1}\right)$ (solid fuel) \\
\hline$T_{0}$ & Ambient temperature $(\mathrm{K})$ & $\tau$ & Characteristic time (s) \\
\hline$u_{j}$ & Velocity vector component $\left(\mathrm{m} \mathrm{s}^{-1}\right)$ & \multicolumn{2}{|c|}{ subscripts } \\
\hline$U$ & Gas flow velocity $\left(\mathrm{m} \mathrm{s}^{-1}\right)$ & $G$ & Gas phase \\
\hline$U_{10}$ & $10 \mathrm{~m}$ open wind velocity & OT & Optical thickness \\
\hline & & Res & Fire residence time \\
\hline$t$ & Time (s) & $s$ & Solid fuel \\
\hline$W$ & TKE buoyancy production term & S & Soot particles \\
\hline
\end{tabular}




\section{INTRODUCTION}

The dynamics of a surface fire propagating through a homogeneous vegetation layer is governed by the exchange of mass, energy and momentum occurring at the interface separating solid particles, composing the fuel layer, with the surrounding atmosphere. In considering the local conservation equations which control these physical mechanisms, one can notice that the exchange terms between the solid and the gaseous phase are proportional to the specific surface $a$ separating these two media (often called the Leaf Area Density in the literature). This characteristic of the solid fuel layer is defined as the product of the solid phase volume fraction $\left(\alpha_{S}\right)$ with half of the surface area to volume $(\mathrm{SA} / \mathrm{V})$ ratio $\left(\sigma_{S}\right)$ as follows:

$a=\frac{\alpha_{S} \times \sigma_{S}}{2}$.

For solid fuel particles such as disks or cylinders, the SA/V is inversely proportional to the thickness characterizing these particles. Combined with the density, volume fraction and moisture content of burning fuels, this is one of the main physical properties affecting the behaviour of fires. In one of the most used fire spread models (Behave) this parameter affects, at different levels, the rate of spread (ROS) of the fire: the fraction of the heat release by the fire compared to the heat flux absorbed by the solid fuel layer, and the exponent representing the effect of the wind speed [1]. For fires propagating under a zero wind condition, small scale experiments carried out in pine needles [2] fuel beds and in eucalypt forest fuels [3], have shown that the fire residence time and the SA/V were related as follows:

$$
\tau_{\operatorname{Re} s}=\frac{A}{\sigma_{S}^{B}}
$$

The constants $A$ and $B$ (Eq.2) vary from one study to the other as follows: $A=75600, B=1$ in [2], $A=$ 208487, $B=1.236$ in [3]. The consequence of the relationship found in [2] is that the time characterizing the travel of the fire front depends only on the geometrical characteristics of the solid fuel particles composing the vegetation layer. The fact that the exponent $B$ is different from unity in [3] suggests that another length scale, in addition to the fuel particles thickness, may affect the fire residence time. In the same paper [3], the author suggests that other heat transfer mechanisms (such as convection) can also affect this characteristic time and consequently the volume fraction $\left(\alpha_{S}\right)$ must also affect the constant $A$ in equation (2).

The combination of predictions obtained using a semi-empirical fire spread model (such as Behave) with real data collected from well documented wildfires [4], has shown that the integration of the effects of the slope angle and wind speed velocity on the resulting plume used to evaluated the rate of spread (in place of the general meteorological wind conditions), constitutes a major issue needed in order to improve the quality of predictions of operational fire spread models. Recently, the coupling of an empirical forest fire spread model with a mesoscale atmospheric model (ForeFire-MesoNH) has been proposed to simulate, at large scale, the propagation and smoke emissions of wildfires $[5,6]$. In this kind of model, the fire front is represented as a thick line and the depth of the front is calculated from the fire residence time evaluated using the expression proposed by Anderson [2]. As suggested in [3], a significant question is how to be sure that this characteristic time depends only on the geometrical characteristics (such as the SA/V) of the solid fuel particles composing the vegetation layer? The main part of this paper will tackle this question.

\section{MATHEMATICAL MODEL}

The problem of the propagation of a surface fire through a homogeneous vegetation layer has been studied numerically using a multiphase formulation. This approach initially proposed by Grishin [7] has been extended with success to simulate in $2 \mathrm{D}$ and $3 \mathrm{D}$ the behaviour of surface and crown fires in numerous situations $[8,9,10]$. The solid phases representing the various solid fuel elements (foliage, twigs, trunk, etc.) composing the vegetation, has been represented in a similar manner as a set of weakly dense porous continuum media immersed in a gaseous phase. The internal structure of the solid fuel elements has been represented using 4 basic components (water, dry matter, char and ash), where each one was described using its own set of physical properties (mass fraction, specific heat, thermal conductivity, etc.). In assuming that the solid fuel elements of the vegetation stayed at rest, the evolution of the state of the 
vegetation (mass, volume, composition, and temperature) were governed by a set of Ordinary Differential Equations (ODE's) obtained from the conservation equations for mass and energy. Part of the terms located on the right hand side of these equations reproduced the difference steps of degradation of the vegetation (drying, pyrolysis and char combustion) resulting from the intense heating coming from the fire front. The degradation rates characterizing these processes were evaluated experimentally from thermal analysis of Mediterranean fuel samples. The evolution of the gaseous phase was governed by the various physical mechanisms occurring inside the atmosphere surrounding the fire front: atmospheric turbulence and canopy turbulence interactions, mixing and combustion between gaseous pyrolysis products and ambient air, and radiation from the gas + soot mixture.

In considering that the general trend of the effects of the SA/V upon the propagation of a surface fire was not considerably affected by $3 \mathrm{D}$ effects, the present numerical simulations were conducted using a $2 \mathrm{D}$ configuration with $X$ denoting the direction of fire propagation and $Z$ the vertical direction. On a flat terrain under moderate wind conditions a significant portion of the flame/vegetation interaction comes from the part of the flame which is located both inside and just above the vegetation layer, where it is minimally affected by these 3D effects. A vegetation layer of $0.7 \mathrm{~m}$ depth and $70 \mathrm{~m}$ long has been positioned at a distance equal to $20 \mathrm{~m}$ from the inlet of the computational domain. This distance has been considered as sufficient for the establishment of a boundary layer profile ahead of the ignition line. The physical properties of the solid fuel particles composing the vegetation is summarized in Table 1. With these values, the Leaf Area Index $(\mathrm{LAI}=0.5 \times$ volume fraction $\times \mathrm{SA} / \mathrm{V} \times$ vegetation depth) characterizing the vegetation layer was varied between 0.35 and 4.2. All calculations were conducted with the same wind conditions, with the inlet velocity profile assumed to be logarithmic and the level of the wind intensity, defined $10 \mathrm{~m}$ above the ground (the $10 \mathrm{~m}$ open wind velocity) equal to $4 \mathrm{~m} / \mathrm{s}$.

Table 1. Physical properties of the vegetation layer.

\begin{tabular}{|l|c|}
\hline Density $\left(\mathrm{kg} / \mathrm{m}^{3}\right)$ & 500 \\
\hline Volume fraction & 0.002 \\
\hline Fuel moisture content & $10 \%$ \\
\hline Surface Area to Volume ratio $(\mathrm{SA} / \mathrm{V})\left(\mathrm{m}^{-1}\right)$ & $500-6000$ \\
\hline
\end{tabular}

In the gas phase, the problem has been formulated using a two-step averaging procedure. The first step, in space, has been performed to take into account the presence of the vegetation in the mass, momentum and energy conservation equations (similar to a homogenization procedure). As indicated previously, the vegetation has been represented as sets of solid fuel particles, immersed inside the gaseous phase (as a sparse porous media). Multiple interactions resulting from the exchange of mass (water vapor, pyrolysis products), momentum (drag forces) and energy between the solid and the gas phase, have been taken into account by additional source terms in the equation governing the behaviour of the gaseous phase (Euler/Euler method for the resolution of multiphase flows). The second step, in time, has been introduced to solve for turbulence. For this study a TRANS approach has been adopted (RNG k- $\varepsilon$ turbulence model) $[12,13]$, adding additional terms to take into account the production and destruction of turbulence resulting from the flow/canopy interaction (terms proportional to the drag coefficient $C_{D}$ ):

$$
\begin{aligned}
& \frac{D \bar{\rho} K}{D t}=\frac{\partial}{\partial x_{j}}\left(\frac{\mu_{e f f}}{\operatorname{Pr}_{T}} \frac{\partial K}{\partial x_{j}}\right)+P+W-\rho \varepsilon+\rho C_{D} \frac{\alpha_{S} \sigma_{S}}{2}\left[\widetilde{U}^{3}-4 \widetilde{U} K\right] \\
& \frac{D \bar{\rho} \varepsilon}{D t}=\frac{\partial}{\partial x_{j}}\left(\frac{\mu_{e f f}}{\operatorname{Pr}_{T}} \frac{\partial \varepsilon}{\partial x_{j}}\right)+C_{\varepsilon 1} \frac{P}{T}+C_{\varepsilon 3} \frac{W}{T}-\rho\left(C_{\varepsilon 2}+R\right) \frac{\varepsilon}{T}+\rho C_{D} \frac{\alpha_{S} \sigma_{S}}{2}\left[\frac{3}{2} \frac{\varepsilon}{K} \widetilde{U}^{3}-6 \widetilde{U} \varepsilon\right] \\
& \mu_{T}=\rho C_{\mu} \frac{K^{2}}{\varepsilon} \times f_{\mu} \quad f_{\mu}=\exp \left[-\frac{2.5}{1+0.02 R_{e T}}\right] \quad \operatorname{Re}_{T}=\frac{\rho K^{2}}{\mu \varepsilon}
\end{aligned}
$$


where $T=\max \left(\tau, \mathrm{C}_{\mathrm{T}} \tau_{n}\right)$ is the maximum value between the turbulence time scale $(\tau=\mathrm{K} / \varepsilon)$ and a value $\left(C_{\mathrm{T}}=6\right)$ proportional to the Kolmogorov time scale $\tau_{n}=(v / \varepsilon)^{\prime 2}$, and $\operatorname{Re}_{\mathrm{T}}$ and $\operatorname{Pr}_{\mathrm{T}}$ are the turbulent Reynolds and Prandtl number, respectively.

where $\mu_{\text {eff }}$ represents the effective viscosity i.e. the sum of the molecular and the turbulent contribution.

The following set of constants, have been introduced in the turbulence model [13]:

$\mathrm{C}_{\mathrm{t} 1}=1.42, \mathrm{C}_{\mathrm{t}}=1.68, \mathrm{C}_{\mathrm{t}}=1.5, \mathrm{C}_{\mathrm{n}}=0.085$

$\mathrm{P}$ and $\mathrm{W}$ are respectively the terms contributing to the production of turbulence, due to shear and buoyancy effects, given as:

$$
P=-\overline{\rho u_{i}^{\prime \prime} u_{j}^{\prime \prime}} \frac{\partial \tilde{u}_{i}}{\partial x_{j}} \quad W=-\frac{\mu_{T}}{\bar{\rho}^{2}} \frac{\partial \bar{\rho}}{\partial x_{j}} \frac{\partial \widetilde{p}}{\partial x_{j}}
$$

Near the fire front, due to the presence of hot spots (hot gases, burning particles, etc.), the pyrolysate (mainly $\mathrm{CO}$ and $\mathrm{CH}_{4}$ ), resulting from the decomposition of the vegetation, react very quickly with the ambient air, with a quasi infinite reaction rate (high Damköhler number). Therefore, we can postulate that the reaction rate is not limited by chemical kinetics, but by the time necessary for the mixing between the gaseous fuel and the oxygen. This mixing is primarily ensured by the turbulent structures (eddies) located in the flaming zone. In this case, the reaction rate can be written as a function of the local mass of fuel available for burning divided by the integral turbulent time scale (the Eddy Dissipation Combustion Concept) [14]:

$$
\overline{W_{F u e l}^{E D C}}=\frac{C_{A} \bar{\rho}}{\tau_{\text {mix }}} \times \min \left(Y_{\text {Fuel }}, \frac{Y_{\text {Oxy }}}{v}\right) \quad C_{A}=\frac{23.6}{R_{e T}^{1 / 4}} \times \frac{\chi}{\left(1-\chi \gamma^{*}\right)}
$$

where $Y_{\text {Fuel }}$ and $Y_{\text {Oxy }}$ denote the mass fraction of Fuel and Oxygen, respectively, $v$ is the stoichiometric ratio of the combustion reaction, and $\mathrm{C}_{\mathrm{A}}$ is a function of the turbulent Reynolds number [14].

where $\gamma *$ is the volume fraction of the small scale turbulent structures and $\chi$ the fraction occupied by the reaction zone inside these small structures, defined as the following:

$$
\chi=\frac{Y_{\operatorname{Pr} o} /(1+v)}{\gamma_{\lambda}\left[Y_{\text {Fuel }}+Y_{\operatorname{Pr} o} /(1+v)\right]} \quad \gamma_{\lambda}=\frac{2.13}{R_{e T}^{3 / 4}}
$$

As the amount of burned fuel does not exceed the quantity locally available, the mixing time $\tau_{\text {mix }}$ has been evaluated from the characteristic time defined for the turbulent flow $\left(\tau_{\operatorname{mix}}=\mathrm{K} / \varepsilon\right)$.

In considering the important role played by radiation heat transfer in such problems [15], the turbulence radiation interaction (TRI) resulting from the fluctuations of temperature and soot volume fraction in the flame have been taken into account in the radiation transfer equation (RTE) using an optically thin fluctuation approximation (OPFA) [16, 17]:

$$
\begin{aligned}
& \frac{d \alpha_{G} \bar{I}}{\mathrm{ds}}=\alpha_{G}\left(\frac{\sigma \overline{\sigma_{a} T^{4}}}{\pi}-\overline{\sigma_{a}} \bar{I}\right)+\frac{\sigma_{S} \alpha_{S}}{4}\left(\frac{\sigma T_{S}^{4}}{\pi}-\bar{I}\right) \\
& \overline{\sigma_{a} T^{4}} \approx \overline{\sigma_{a}} \bar{T}^{4}\left[1+6 \overline{\frac{T^{\prime 2}}{\bar{T}^{2}}}+4 \overline{\frac{\sigma_{a}^{\prime} T^{\prime}}{\overline{\sigma_{a}}} \bar{T}}\right]=\overline{\sigma_{a}} \bar{T}^{4}\left[1+6 \overline{\frac{T^{\prime 2}}{\bar{T}^{2}}+4 \overline{\bar{T}^{\prime 2}}} \frac{\partial \sigma_{a}}{\overline{\sigma_{a}}} \overline{\partial T}\right] \\
& \frac{\partial \sigma_{a}}{\partial T}=1862 \times \alpha_{\text {soot }}
\end{aligned}
$$


The transport equation governing the temperature variance $\overline{T^{\prime^{2}}}=\theta$ has been approximated as follows [18, 19]:

$$
\frac{D \bar{\rho} \theta}{D t}=\frac{\partial}{\partial x_{j}}\left(\frac{\mu_{e f f}}{\operatorname{Pr}_{T}} \frac{\partial \theta}{\partial x_{j}}\right)+2 P_{\theta}-2 \varepsilon_{\theta} \quad P_{\theta}=\frac{\mu_{T}}{\operatorname{Pr}_{T}}\left(\frac{\partial \bar{T}}{\partial x_{j}}\right)^{2} \quad \varepsilon_{\theta}=\rho \frac{\theta}{2 \times R} \times \frac{\varepsilon}{K}
$$

In agreement with experimental observations, the ratio of scalar and velocity dissipation time (R) has been assumed to be equal to $0.5[18,19]$.

The set of transport equations governing the evolution of state of the gas phase were solved using a Finite Volume method (FV) and a segregated iterative algorithm (PISO) for the pressure/velocity coupling. To avoid the introduction of false numerical diffusion, the Ultra-Sharp approach (Universal Limiter for Tight Resolution and Accuracy Resolution Program) has been adopted for the treatment of convective terms in the convection-diffusion transport equations in the gas phase [20]. For discretisation in space, a $3^{\text {rd }}$ order QUICK scheme has been used for the convective terms [21] and a $2^{\text {nd }}$ order central difference scheme was used for the diffusion terms. The time integration was performed using a $2^{\text {nd }}$ order implicit Euler scheme. The set of ODE governing the evolution of the state of the vegetation was solved using a Runge Kutta method.

As indicated in [15], to ensure an accurate representation of the propagation of fire through a vegetation layer, it is crucial to choose the mesh size using physical criteria: the mesh size $\Delta$ must be smaller than the fuel depth $\left(\Delta<\mathrm{H}_{\text {Fuel }}\right)$ and the length of extinction $\left(\Delta<2 \mathrm{xH}_{\text {Fuel }} / \mathrm{LAI}\right)$.

For more details concerning the model (physical formulation and numerical methods) and also the confrontation between numerical results obtained using this model and experimental data collected on the field for shrubland and grassland fires, the reader is invited to consult previous published papers [8, 11].

\section{RESULTS AND DISCUSSION}

As reported in previous papers, a large part of the dynamics characterizing the propagation of surface fires depends on two forces governing the trajectory of flames, the buoyancy from the difference of density between the ambient air and the thermal plume and the inertia from the wind flow. The ratio of power between these two forces defines a non-dimensional parameter, called the convective Byram number:

$$
I_{B}=\dot{m} \times \Delta H \quad N_{C}=\frac{2 g I_{B}}{\rho C_{P} T_{0}\left(U_{10}-R O S\right)^{3}}
$$

where $\Delta \mathrm{H}=18000 \mathrm{~kJ} / \mathrm{kg}$ designates the heat of combustion, $g$ the acceleration of gravity, $\rho$ the air density, and $T_{0}$ and $C_{P}$ the temperature and specific heat of ambient air. For all numerical simulations, the convective Byram number was varied between 6 and 26.3. Consequently, except for the first case (SA/V = $500 \mathrm{~m}^{-1}$ and $N_{C}=6$ ), we can conclude that all surface fires reproduced in this paper can be more or less be classified as plume dominated fires. In this formula the rate of spread (ROS) has been deduced from the slope of the time evolution of the position of the head of the pyrolysis front (the isotherm where $T_{S}=500$ $\mathrm{K})$.

The results reported in Fig. 1 represent a snapshot of the solid fuel temperature calculated at different times but at the same location (this is also the case for Figures 2, 3 and 4) for three values of the surface area to volume ratio (SA/V): 500, 2000 and $3000 \mathrm{~m}^{-1}$. The Leaf Area Indexes (LAI) associated to these three values of SA/V were equal to $0.35,1.4$ and 2.1 , respectively. In the literature $[7,15]$ the value of LAI/2 represents also the optical thickness of the vegetation layer, i.e. the ratio between the depth of the solid fuel layer by the extinction length scale. With these values, the vegetation layer can be considered as more or less optically thin [19]. Without assuming the mechanisms of heat transfer (convection or radiation) which governs the propagation of fire, we can observe that the increase in the absorption coefficient characterizing the vegetation layer contributes to improved heat transfer between the flame and the solid fuel layer and consequently to an increase in the average value of the solid fuel temperature. 
If the vegetation strata is dense enough $\left(\mathrm{SA} / \mathrm{V}>2000 \mathrm{~m}^{-1}\right)$ we do not observe a great attenuation of the solid fuel temperature profile along the vertical direction. All these observations are confirmed in Fig. 2 and 3, representing the longitudinal (streamwise direction) distribution of temperature (gas and solid) and the dry fuel and water density, calculated for SA/V $=500 \mathrm{~m}^{-1}$ (Fig. 2) and SA/V $=2000 \mathrm{~m}^{-1}$ (Fig. 3). These temperature profiles have been calculated inside $(Z=0.35 \mathrm{~m})$ and at the top of the canopy $(\mathrm{Z}=0.7 \mathrm{~m})$. The detailed analysis of these temperature profiles have shown that for $\mathrm{SA} / \mathrm{V}=500 \mathrm{~m}^{-1}$ (Fig. 2), the temperature of the gas was larger than the temperature of the solid fuel in the region located just ahead of the fire front.
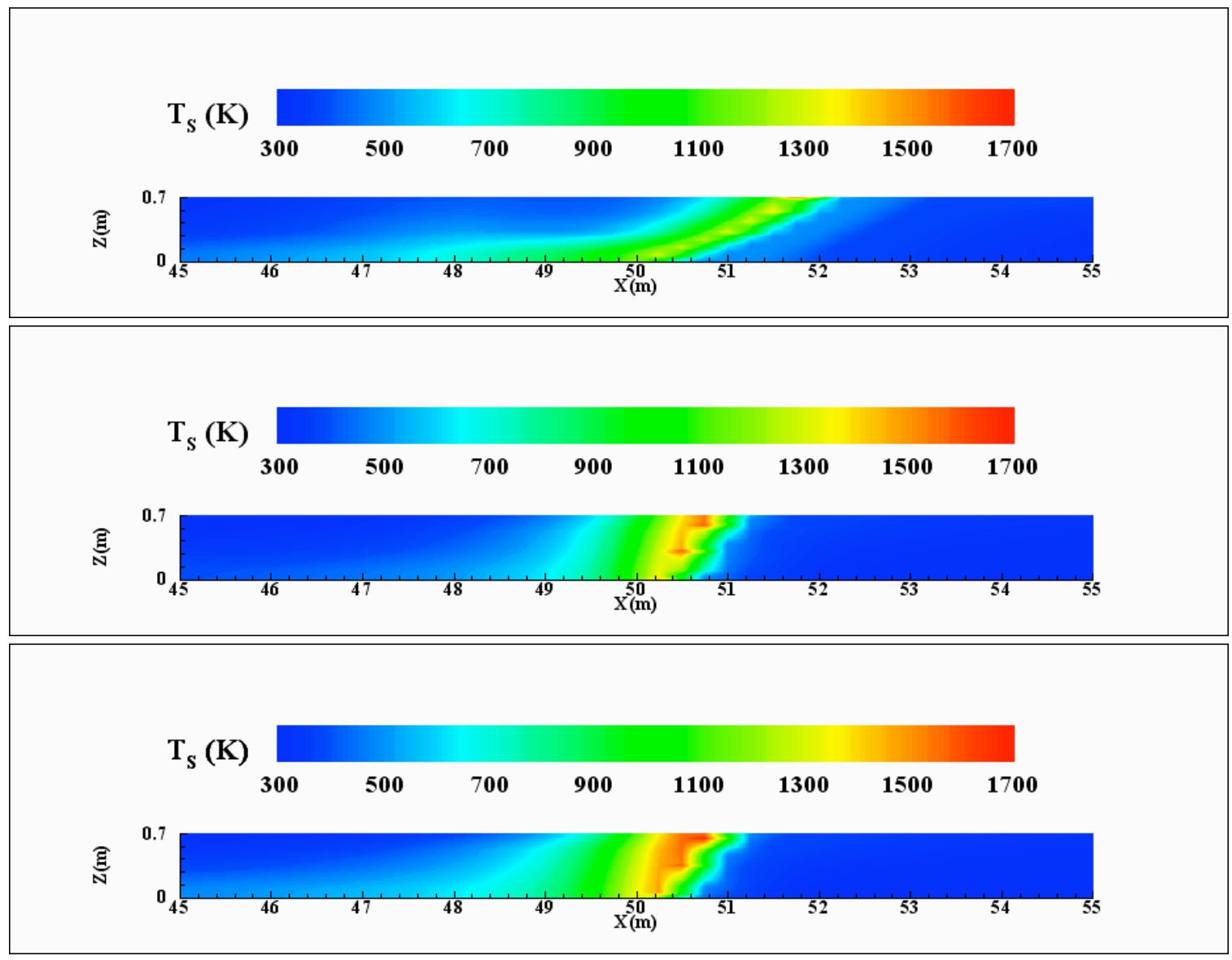

Fig. 1. Solid fuel temperature field (snapshot) calculated for three values of the surface area to volume ratio $\mathrm{SA} / \mathrm{V}\left(500,2000\right.$ and $\left.3000 \mathrm{~m}^{-1}\right)$. 

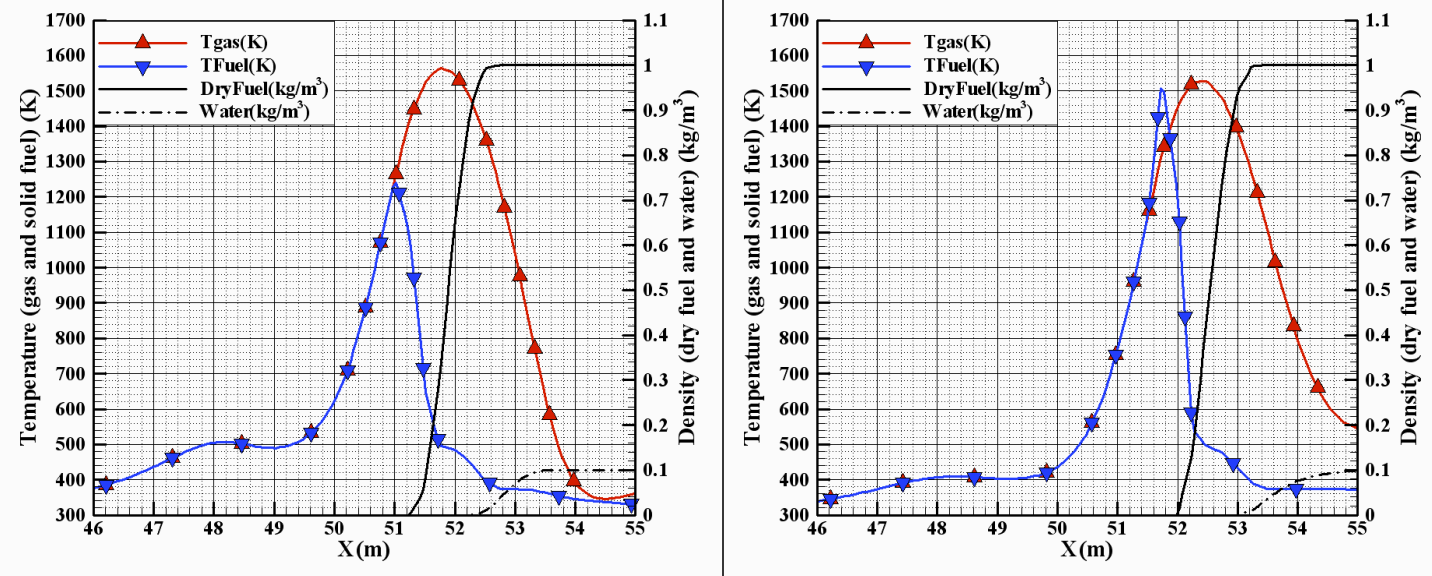

Fig. 2. Distribution of gas and solid fuel temperature and dry fuel and water density, at mid distance from the ground $(Z=0.35 \mathrm{~m}$, on left $)$ and at the top of the canopy $(\mathrm{Z}=0.7 \mathrm{~m}$, on right $)$ for a $\mathrm{SA} / \mathrm{V}=500 \mathrm{~m}^{-1}$.
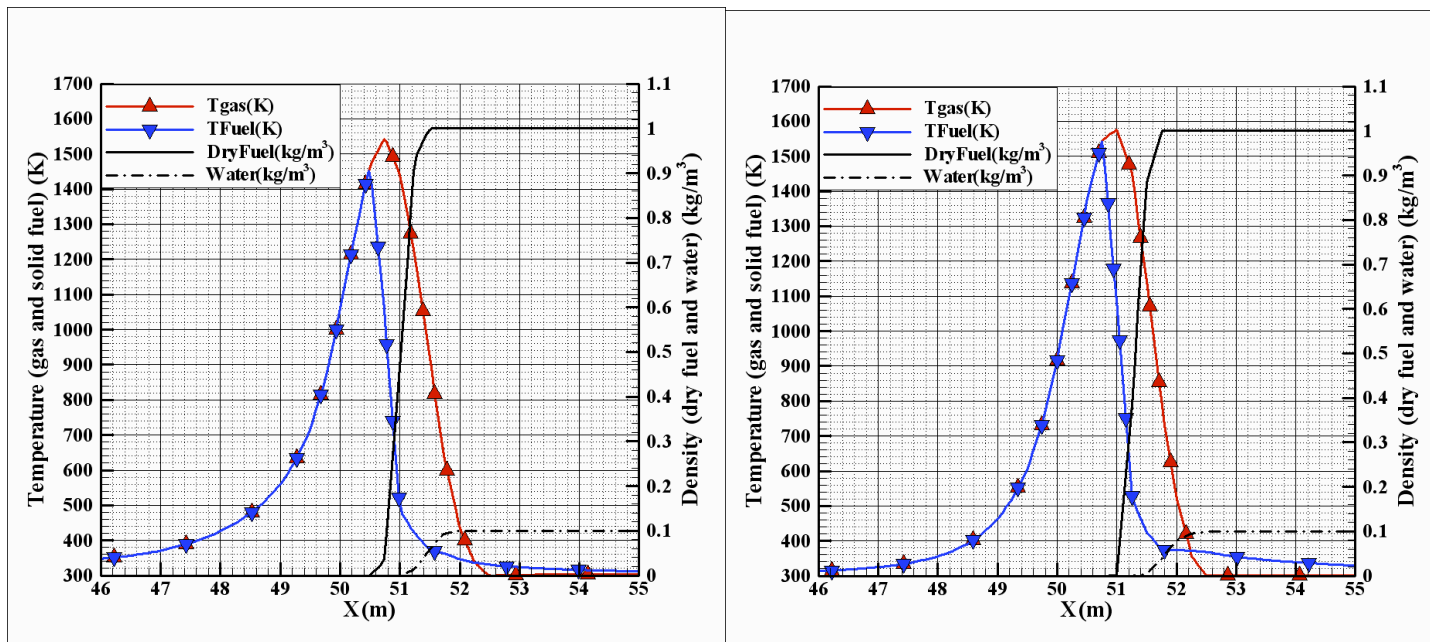

Fig. 3. Distribution of gas and solid fuel temperature and dry fuel and water density at mid distance from the ground $(Z=0.35 \mathrm{~m}$, on left $)$ and at the top of the canopy $(\mathrm{Z}=0.7 \mathrm{~m}$, on right $)$, for a $S A / V=2000 \mathrm{~m}^{-1}$.

The snapshot in time of this particular configuration suggests the heating process governing the propagation of the fire are partially driven by convective heat transfer. For SA/V $=2000 \mathrm{~m}^{-1}$, even if the gas remains hotter than the solid in a large part of the fuel layer, we notice the two curves intersect (where the temperature of the solid phase became larger than the temperature of the gas phase) in a small region located ahead of the fire front (similar results occur for larger values of SA/V). This configuration indicates that, in this case, the solid fuel layer was preheated exclusively by radiation, then in the region located adjacent to the fire front both convection and radiation heat transfer can contribute to the propagation of the fire. The combination of these two modes of heat transfer in the near vicinity of the flame front may also represent the 'flame contact' mechanism reported in [22]. These observations were confirmed by a snapshot of the gas temperature fields reproduced in Fig. 4. This figure has highlighted that for SA/V $=500$ $\mathrm{m}^{-1}$ the flame trajectory was more affected by the wind flow and the thermal plume arrived to impact the unburned solid fuel located ahead the fire front. In analyzing the data reported in Table 2, we can notice that above a SA/V equal to $1000 \mathrm{~m}^{-1}$ all the results concerning the rate of spread, the mass loss rate, the fire line intensity and the convective Byram number have nearly the same values and are therefore not significantly affected by a variation (from 1000 to $4000 \mathrm{~m}^{-1}$ ) of the SA/V. This is not the case concerning the results obtained for a SA/V equal to $500 \mathrm{~m}^{-1}$, for which we notice a reduction by a factor 2 of the ROS, 
the mass loss rate and of the fire line intensity, and also a reduction by a factor ranged between 3 and 4 of the convective Byram number. This result is a new confirmation of the very important role played by $\mathrm{N}_{\mathrm{C}}$ concerning the regimes of propagating surface fires and sudden changes in fire behaviour. We know that this phenomenon occurs for $\mathrm{N}_{\mathrm{C}}$ around unity, corresponding to the transition from plume dominated fires to wind driven fires. The heat flux exchanged by convection (blue gradient) and radiation (red triangle) has been calculated for the whole vegetation layer and is reported in Figure 5 for the 6 reported values of SA/V. This curve clearly highlights that the radiation heat flux reaches an optimal value when the extinction length is equal to the vegetation depth (optical thickness $=1$ ), and then decreases, whereas at the same time the convective heat transfer increases due to the augmentation of the solid/gas exchange surface. This mechanism contributes to the intersection of these two curves and for a value of SA/V equal to $6000 \mathrm{~m}^{-1}$, the convective heat transfer becomes the dominant mode of heat transfer.

The fire residence time $\tau_{\text {Res }}$ representing the traveling time of the fire front, i.e. the duration of time at which a point located on the trajectory of a fire can be considered inside the burning zone. This characteristics time can be determined from the time history of the solid fuel temperature curve, calculated at various points inside the vegetation layer $(Z=0.25 \mathrm{~m})$ (see Fig. 6).
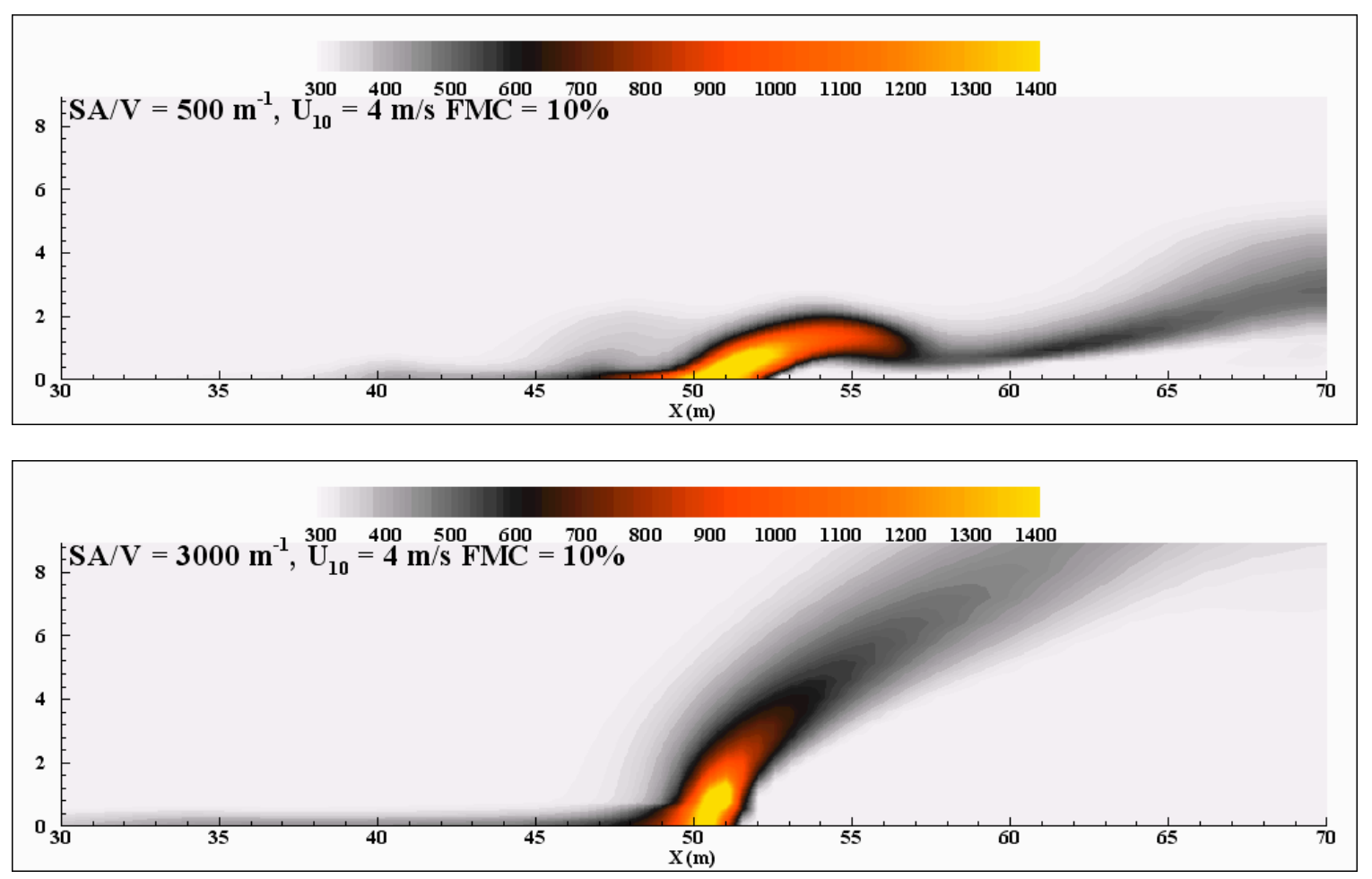

Fig. 4. Temperature field (gas phase) calculated for two values of the SA/V characterizing the vegetation layer $\left(\mathrm{SA} / \mathrm{V}=500 \mathrm{~m}^{-1}\right.$ (on top) and $3000 \mathrm{~m}^{-1}$ (on bottom)). 


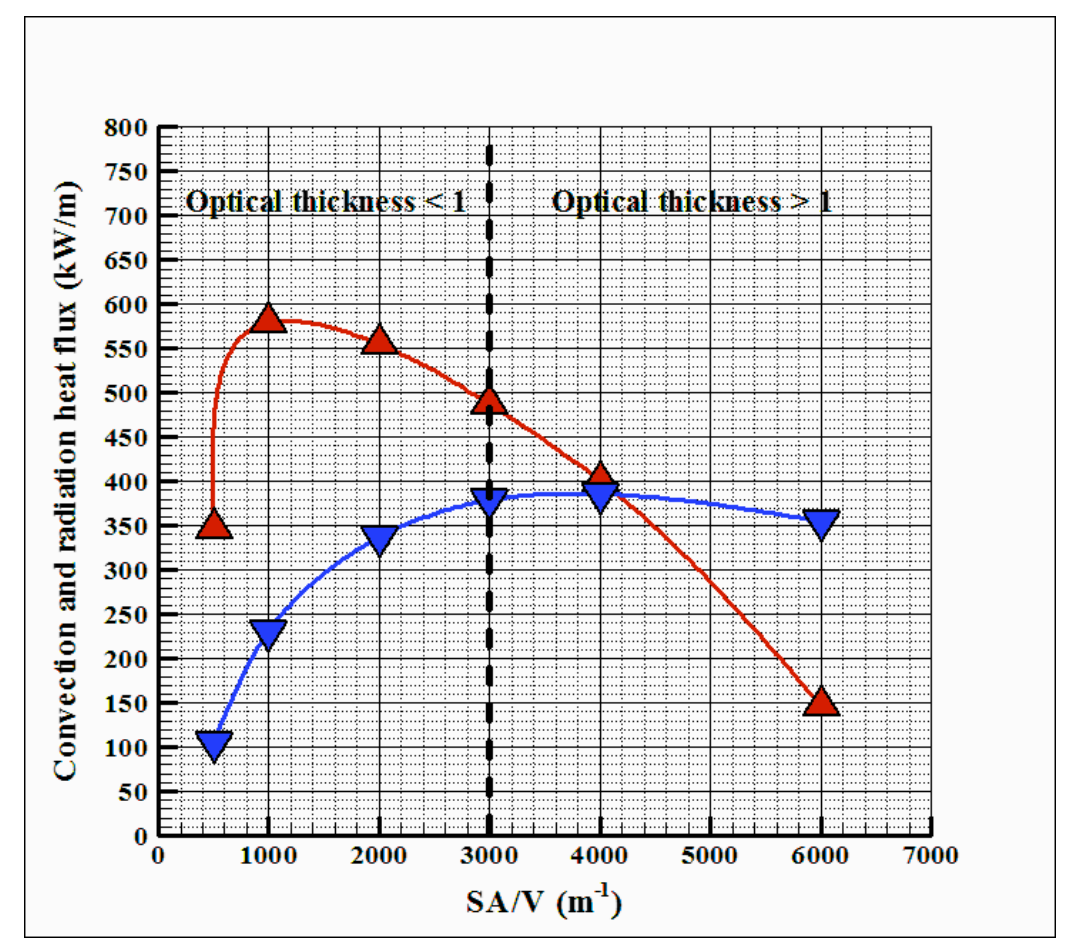

Fig. 5. Heat flux exchange by convection (blue gradient) and radiation (red triangle) between the vegetation layer and the surrounding atmosphere for various values of the SA/V characterizing the solid fuel particles.

Table 2. Rate of spread, mass loss rate, fire line intensity and Byram convective number versus SA/V.

\begin{tabular}{|c|c|c|c|c|c|c|}
\hline $\mathrm{SA} / \mathrm{V}\left(\mathrm{m}^{-1}\right)$ & 500 & 1000 & 2000 & 3000 & 4000 & 6000 \\
\hline $\mathrm{ROS}(\mathrm{m} / \mathrm{s})$ & 0.584 & 1.187 & 1.242 & 1.238 & 1.272 & 1.118 \\
\hline${\mathrm{m}\left(\mathrm{kg} \mathrm{m}^{-1} \mathrm{~s}^{-1}\right)}^{0.287}$ & 0.598 & 0.627 & 0.615 & 0.614 & 0.599 \\
\hline $\mathrm{I}_{\mathrm{B}}(\mathrm{kW} / \mathrm{m})$ & 4493 & 9305 & 9844 & 9657 & 9629 & 9448 \\
\hline $\mathrm{N}_{\mathrm{C}}$ & 6.04 & 23.11 & 26.23 & 25.34 & 26.22 & 21.82 \\
\hline$\tau_{\mathrm{OT}}$ & 0.175 & 0.35 & 0.7 & 1.05 & 1.4 & 2.1 \\
\hline
\end{tabular}

The curves reported in Fig. 6 clearly highlight that, except for the point located in the burner used to ignite the fuel $(X=20 \mathrm{~m})$, the curves obtained for $X=40,50$ and $60 \mathrm{~m}$, converge rapidly toward a homothetic behaviour and seem to be similar. Using these curves, the fire residence time has been defined as the duration of time for which the solid fuel temperature was larger than $700 \mathrm{~K}$ (see Fig. 6). For a quasi-steady state propagating fire with a constant rate of spread (ROS), the fire residence time can also be defined as the ratio between the fire front depth by the ROS.

From small scale experiments carried out in solid fuel beds, various authors have suggested that the fire residence time could be more or less proportional to the thickness of solid fuel particles, i.e. more or less inversely proportional to the SA/V $[2,3]$.

To test the validity of this proposal at larger scale, the evolution of the fire residence time versus the SA/V has been reported in Fig. 7, and the present numerical results have been compared with two power law functions proposed in references [2, 3] (see also Eq. 2). We notice on this figure that the fire residence time $\left(\tau_{\text {Res }}\right)$ is a decreasing function of the SA/V until SA/V $<2000 \mathrm{~m}^{-1}$. As shown in Table 2, this section of this curve corresponds also to the case for which the vegetation layer was characterized by an optical thickness 
$\tau_{\mathrm{OT}}<0.7$ (the depth of the vegetation layer was smaller than the extinction length scale). For SA/V $=2000$ $\mathrm{m}^{-1}\left(\tau_{\mathrm{OT}}=0.7\right) \tau_{\text {Res }}$ reaches a minimum value equal to $1.7 \mathrm{~s}$, then it increases a little bit and seems to converge slowly toward a more or less constant value. One can notice that the values obtained numerically for the fire residence times (ranged between 1 and $10 \mathrm{~s}$ ) were smaller than those reported in the literature (generally ranging for grasslands between $5 \mathrm{~s}$ to $15 \mathrm{~s}$ ) [23].

The empirical relations given the fire residence time versus the SA/V (Anderson 1969, Burrows 2001) were obtained for relatively dense solid fuel beds (pine needles, eucalyptus leaves) and generally in no wind conditions. The present simulations were carried out for more sparse fuels (with a solid fuel volume fraction at least 10 times smaller than in a solid fuel bed), a taller and quite dry vegetation layer (fuel moisture content equal to $10 \%)$ and under significant wind conditions $(4 \mathrm{~m} / \mathrm{s})$. All these factors have contributed to increased heat transfer between the flame and the unburned vegetation, reducing the fire residence time. In addition, our evaluation of the fire residence time was only based on the depth of the flame in the gaseous phase, at a height of $Z=0.25 \mathrm{~m}$ above the ground level (more easy to evaluate and disconnected from the hot ember front) and choosing a temperature threshold equal to $700 \mathrm{~K}$. It is probably for these reasons that our evaluations of this parameter were a little bit smaller than those reported in the literature.

Even if this choice can introduced a reduction of the fire front depth (and consequently a reduction of the fire residence time), in comparison to what was previously reported in the literature, it will not affect the general trend concerning the relationship between the fire residence time and the SA/V.

To generalize this analysis we have developed a non dimensional parameter, $\tau *$ which is a function of the fire residence time multiplied by the $10 \mathrm{~m}$ open wind velocity and the Leaf Area Density ( $\mathrm{LAD}=\mathrm{a} / 2$ ),

$$
\tau^{*}=\frac{\tau_{\operatorname{Re} s} \times U_{10} \times L A D}{2}
$$

In Fig. 8, we report the evolution of $\tau *$ as a function of $1 / \mathrm{N}_{\mathrm{C}}$, in adding new results obtained for different values of the fuel moisture content (FMC, ranged between $5 \%$ and 120\%) and of the $10 \mathrm{~m}$ open wind speed $\left(\mathrm{U}_{10}\right.$, ranged between 1 and $\left.25 \mathrm{~m} / \mathrm{s}\right)$.

We notice that, for wind driven fires $\left(1 / \mathrm{N}_{\mathrm{C}}>>1\right)$, the reduced fire residence time $\tau *$ converges more or less towards a constant value, nearly equal to 150 . In this case the fire residence time $\tau_{\text {Res }}$ varied inversely proportional to the $\mathrm{SA} / \mathrm{V}$, similar to Eq. 2, with constants A and B nearly equal to the values previously proposed in [2]: $A=75000$ and $B=1$. For situations for which the behaviour of the fire was not fully controlled by the wind flow $\left(1 / \mathrm{N}_{\mathrm{C}}<2\right)$, the situation seems to be more complex to analyze and no universal formula can be extracted concerning a relationship between $\tau_{\text {Res }}$ and $\mathrm{SA} / \mathrm{V}$.

\section{CONCLUSION}

A set of numerical simulations, using a multiphase formulation, has been performed to study the propagation of a surface fire through a homogeneous vegetation layer. The aim of these calculations was to study the role played by the thickness of solid fuel particles upon the behaviour of the fire front, with a particular interest for the fire residence time. In assuming that the solid fuel layer was composed of cylindrical particles, the varied parameter has been the surface area to volume ratio $(\mathrm{SA} / \mathrm{V})$. The numerical results have been compared to empirical correlations from the literature, for which the fire residence time varied more or less proportionally to the particle thickness (inversely proportional to the SA/V). The same kind of behaviour has been found for wind driven fires, characterized by a small convective Byram number $\left(1 / \mathrm{N}_{\mathrm{C}}>>1\right)$. The simulations have also highlighted the role played by the optical thickness $\left(\tau_{\mathrm{OT}}\right)$ characterizing the vegetation layer, in showing that the fire residence time reached a minimum value as $\tau_{\mathrm{OT}}$ $=0.7$, which corresponded to the situation for which the depth of the vegetation layer was nearly equal to 0.7 times the extinction length scale. 


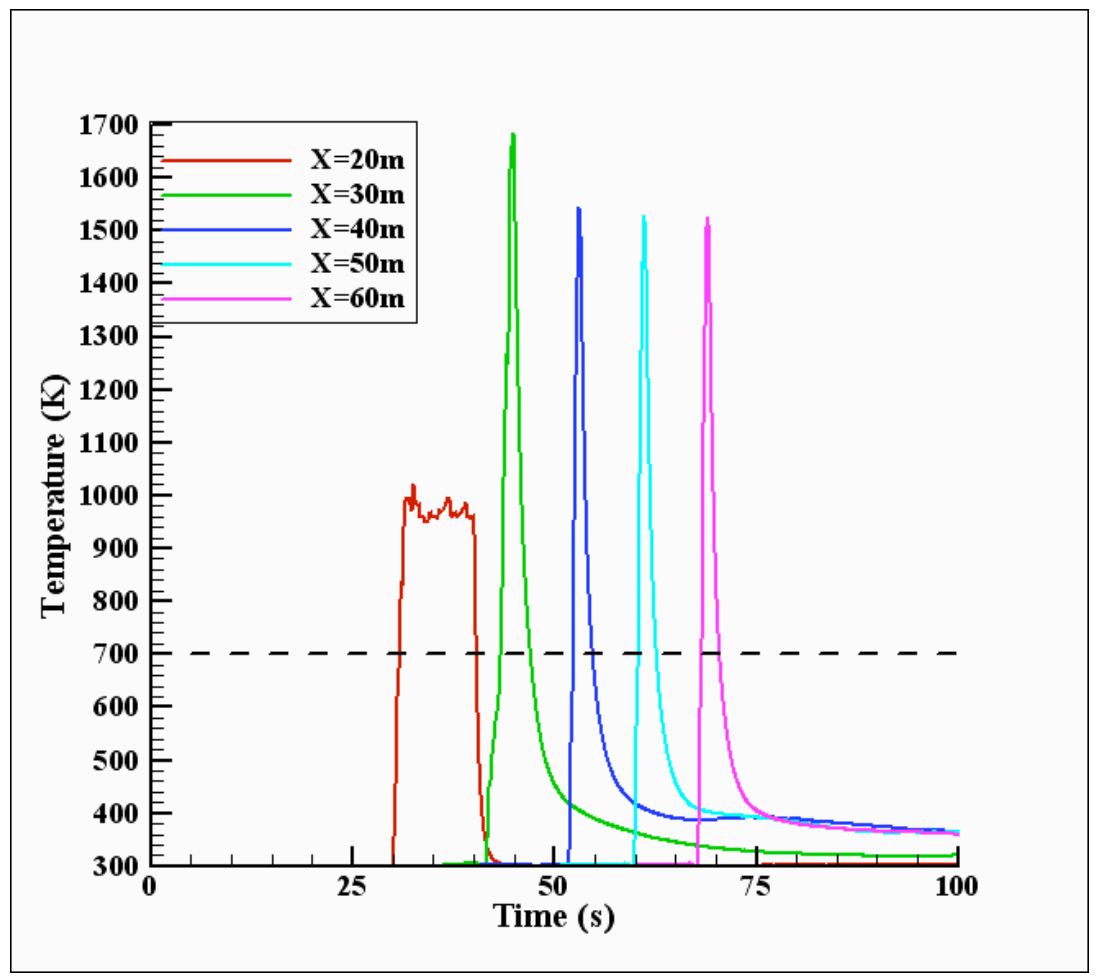

Fig. 6. Time evolution of the solid fuel temperature recorded at various points $(Z=0.25 \mathrm{~m})$ during the propagation of the fire.

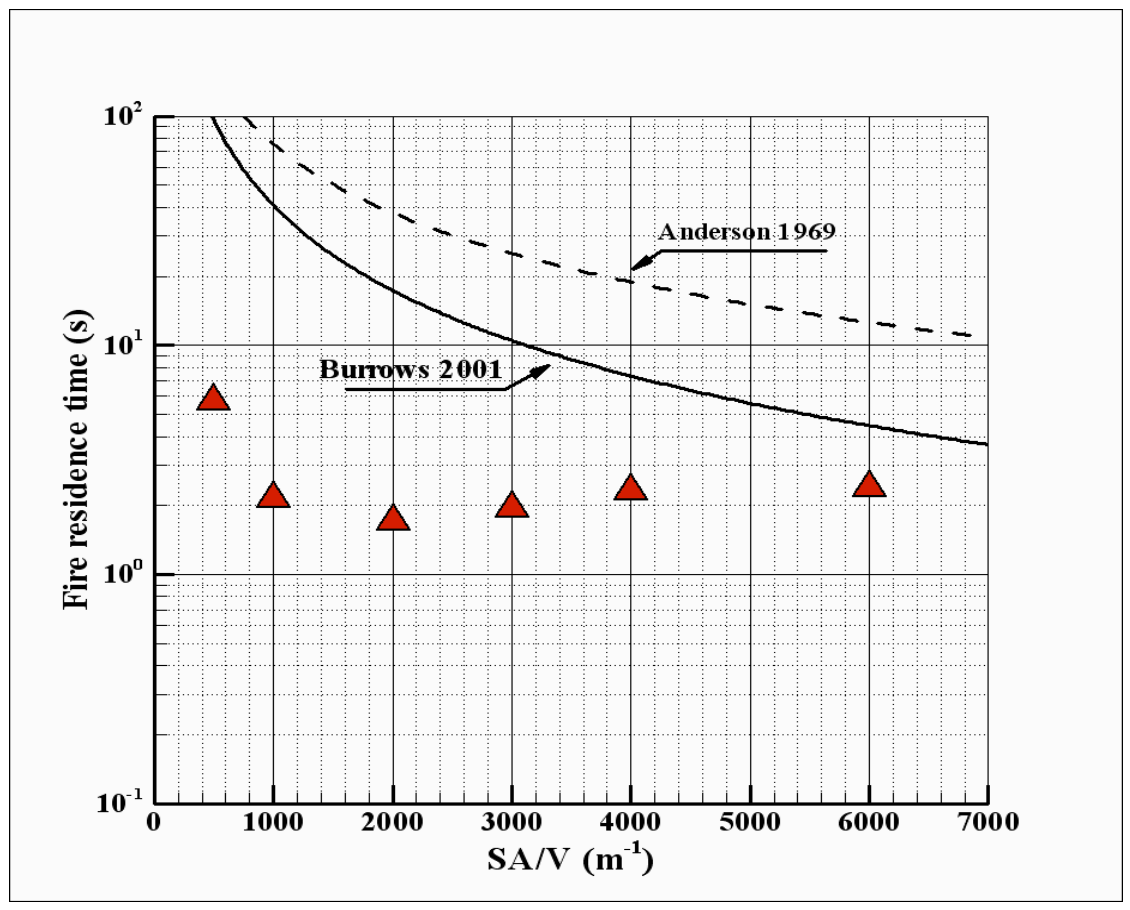

Fig. 7. Fire residence time versus SA/V, present numerical results compared to two empirical models. 


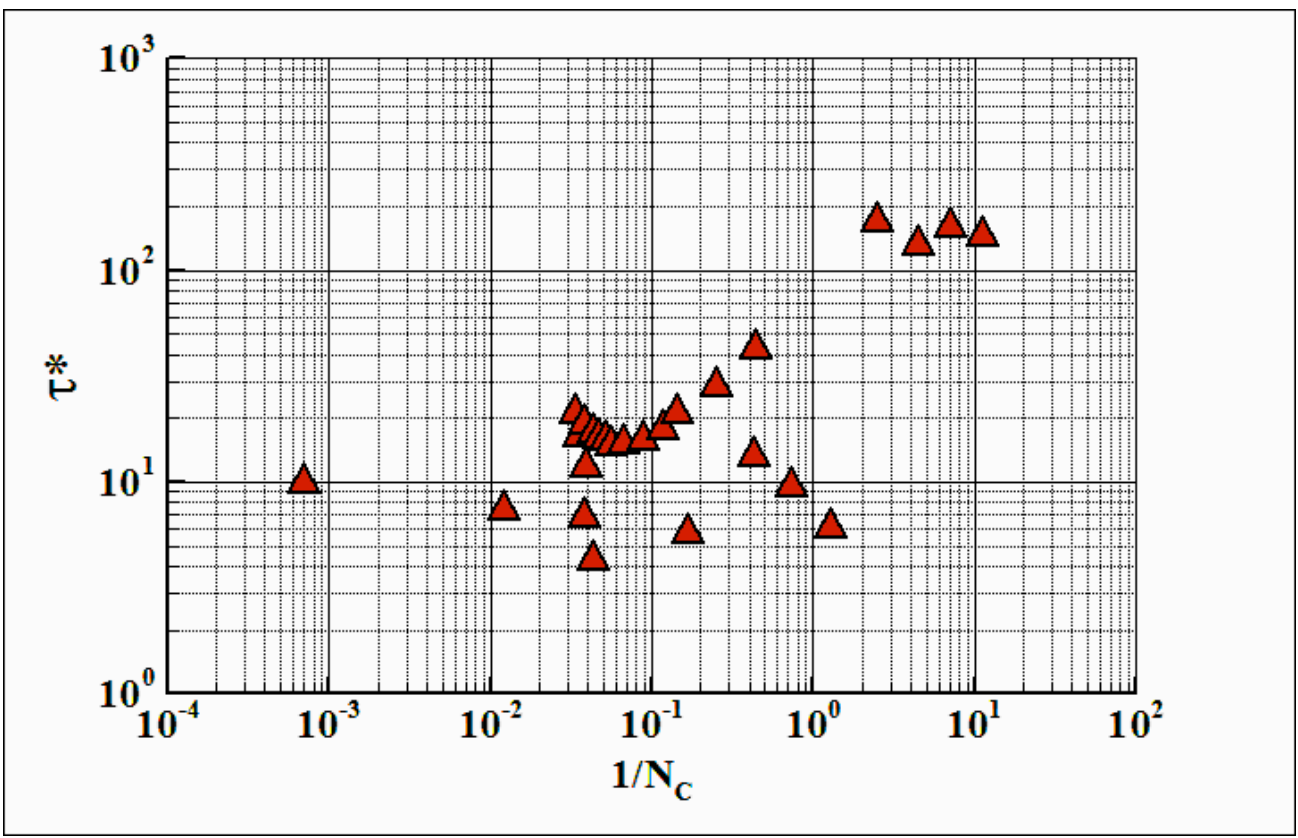

Fig.8 Non-dimensional fire residence time $\tau^{*}$, versus the convective Byram number $\mathrm{N}_{\mathrm{C}}$.

\section{REFERENCES}

[1] Rothermel, R.C. and Anderson, H.E., "Fire spread characteristics determined in the laboratory" USDA Forest Service RP INT-30, 1966, 34p.

[2] Anderson, H.E., "Heat transfer and fire spread” USDA Forest Service RP INT 69, 1969, 20p.

[3] Burrows, N.D., (2001) Flame residence times and rates of weight loss of eucalypt forest fuel particles, Int. J. Wildland Fire, 10: 137-143, http://dx.doi.org/10.1071/WF01005.

[4] Hanson, H.P., Bossert, J.E., Linn, R.R., (2000) The potential and promise of physics-based wildfire simulation, Environment Science Policy, 3: 161-172, http://dx.doi.org/10.1016/S14629011(00)00083-6.

[5] Filippi, J.B., Bosseur, F., Pialat, X., Santoni, P.A., Strada, S., Mari, C., (2011) Simulation of coupled fire/atmosphere interaction with the MesoNH-ForeFire models, Journal of Combustion, Vol.2011, 13.p, http://dx.doi.org/10.1155/2011/540390.

[6] Filippi, J.B., Pialat, X., Clements, C.B., Assessment of ForeFire/Meso-NH for wildland fire/atmosphere coupled simulation of the FireFlux experiment, Proceedings of the Combustion Institute, 2013, 34: 2613-2640, http://dx.doi.org/10.1016/j.proci.2012.07.022.

[7] Grishin A.M., 1997 Mathematical modelling of forest fires and new methods of fighting them. Albini F. (Ed.) Tomsk State University, 1997, 367 p.

[8] Morvan, D., Dupuy J.L., (2004) Modelling the propagation of a wildfire through a Mediterranean shrub using a multiphase formulation. Combustion and Flame, 138: 199-210, http://dx.doi.org/10.1016/j.combustflame.2004.05.001.

[9] Mell, W., Maranghides, A., McDermott, R., Manzello, S.L., (2009) Numerical simulation and experiments of burning Douglas fir trees. Combustion and Flame, 156: 2023-2041, http://dx.doi.org/10.1016/j.combustflame.2009.06.015. 
[10] Morvan, D., Méradji, S., Mell W., (2013) Interaction between head fire and backfire in grasslands, Fire Safety Journal, 58 : 195-203, http://dx.doi.org/10.1016/j.firesaf.2013.01.027.

[11] Morvan, D., Méradji, G. Accary, (2009) Physical modelling of fire spread in grasslands, Fire Safetey Journal, 44: 50-61, http://dx.doi.org/10.1016/j.firesaf.2008.03.004.

[12] Pope, S.B., Turbulent Flows, Cambridge University Press, Cambridge, 2000, 771 p.

[13] Yakhot, V, Orszag, SA, Thangam, S, Gatski, TB, Speziale, CG, (1992) Development of turbulence models for shear flows by a double expansion technique, Physics of Fluids A4(7) : 1510-1520, http://dx.doi.org/10.1063/1.858424.

[14] Magnussen, B.F., Hjertager, B.H., Olsen, J.G., Bhaduri, D. (1979) Effects of turbulent structure and local concentrations on soot formation and combustion in $\mathrm{C}_{2} \mathrm{H}_{2}$ diffusion flames. Proceedings of the Combustion Institute, 17: 1383-1393, http://dx.doi.org/10.1016/S0082-0784(79)80130-7.

[15] Morvan, D., (2011) Physical phenomena and length scales governing the behaviour of wildfires: a case for physical modelling, Fire Technology, 47 (2011), http://dx.doi.org/10.1007/s10694-0100160-2.

[16] Coelho, P.J., (2007) Numerical simulation of the interaction between turbulence and radiation in reactive flow, Progress in Energy and Combustion Science, 33: 311-383, http://dx.doi.org/ 10.1016/j.pecs.2006.11.002.

[17] Siegel, R., Howell, J.R., Thermal radiation heat transfer, Hemisphere publishing corporation, $3^{\text {rd }}$ Edition, Washington, 1992, $1072 \mathrm{p}$.

[18] Béguier, C., Dekeyser, I, Launder, B.E., (1978) Ratio of scalar and velocity dissipation time scales in shear flow turbulence, Physics of Fluids, 21(3): 307-310, http://dx.doi.org/10.1063/1.862228.

[19] Kenjeres, S., Gunarjo, S.B., Hanjalic, (2005) Contribution to elliptic relaxation modeling of turbulent natural and mixed convection, Int. J. Heat and Fluid Flow, 26 : 569-586, http://dx.doi.org/ 10.1016/j.ijheatfluidflow.2005.03.007.

[20] Leonard, B., Mokhtari, S., (1990) Beyond first-order upwinding: the ultra-sharp alternative for non-oscillatory steady-state simulation of convection, Int. J. Numerical. Method in Engineering 30(4): 729-766, http://dx.doi.org/10.1002/nme.1620300412.

[21] Leonard, B.P. (1995) Order of accuracy of QUICK and related convection-diffusion schemes, Applied Mathematical Modelling, 19(11): 640-653, http://dx.doi.org/10.1016/0307904X(95)00084-W.

[22] Finney, M.A., Cohen, J.D., McAllister, S.S., Jolly, W.M. (2012) On the need for a theory of wildland fire spread, Int. J. of Wildland Fire, special issue, http://dx.doi.org/10.1071/WF11117.

[23] Cheney, Ph., Sullivan, A. Grassfires: Fuel, weather and fire behaviour, CSIRO Publishing $\left(2^{\text {nd }}\right.$ Ed.), 2009, 160p.

\section{ACKNOWLEDGMENTS}

This study was partially supported by the Agence Nationale de la Recherche (project number: ANR-09COSI-006). 